\title{
Estudo sobre Finanças Comportamentais e Seus Efeitos na Escolha da Estrutura de Capital
}

\section{Roberta Visnardi Fassina*, Johan Hendrik Poker Junior.}

\section{Resumo}

O projeto propõe que há uma relação entre tendências comportamentais e tomadas de decisões dentro das áreas financeiras de empresas, e que essa relação possa ser explicada e prevista, como são as variáveis dependentes de uma tomada de decisão financeira.

\section{Palavras-chave: \\ Estrutura de Capital, Finanças Comportamentais, Processo Decisório.}

\section{Introdução}

Independentemente de sua formação estrutural de uma empresa, todas estão inseridas na mesma sociedade, com a mesma política, mesma economia, e mesmo ambiente onde estão vulneráveis a infinitos acontecimentos, internos ou externos a empresa, que podem influenciar na sua gestão financeira. Sobre questões variáveis dependentes, há estudos que quantificam os riscos e os tornam numéricos para que sejam, assim, previstos quando se faz um planejamento financeiro. Mas, em contraposição, há variáveis que ainda não são tão quantitativas e fáceis de se medir, que dizem respeito ao comportamento de um gestor ou de um corpo de gestores, e essas são variáveis que possivelmente influenciam diretamente em tomadas de decisões dentro da empresa. Esse projeto de pesquisa foi desenvolvido para que possamos entender o quanto 0 comportamento do corpo de liderança afeta as decisões tomadas dentro da estrutura de capital de uma empresa.

\section{Resultados e Discussão}

Com os resultados da pesquisa, conseguimos perceber que idade e formação são variáveis que podem ter influência na escolha de Estrutura de Capital de uma empresa por parte dos diretores envolvidos nessa tomada de decisão. Como estudado no projeto, as variáveis dependentes que influenciam a EC são mais fáceis de serem previstas, mas como foi proposto nesse projeto, outros fatores podem influenciar um gestor financeiro ao tomar suas decisões, como sua formação, ou quanto tempo de experiência ele tem no seu cargo (onde entra a questão de overconfidence). A proposta desse projeto era testar a hipótese de que a EC pode ser influenciada por outros fatores, entre eles, os citados nessa pesquisa.

\section{Conclusões}

Podemos concluir com os resultados atingidos que a idade e a formação de alguns diretores podem influenciar na tomada de decisão sobre a Estrutura de Capital de sua empresa.

\section{Agradecimentos}

Agradeço por todo apoio e orientação do meu professor e orientador, Johan Poker, e pela ajuda que outros alunos do professor me deram nas coletas de dados para a pesquisa.

BARBERIS, Nicholas; THALER, Richad. Handbook of the Economics of Finance: A Survey of Behavior Finance. New York: Northholland, 2005.

BASTOS, Douglas Dias; NAKAMURA, Wilson Toshiro; BASSO, Leonardo Fernando Cruz. Determinantes da Estrutura de Capital das Companhias Abertas na América Latina: um Estudo Empírico Considerando Fatores Macroeconômicos e Institucionais. Revista de Administração Mackenzie, São Paulo, v. 10, n. 6, p.48-77, dez. 2009. Disponível em: <http://www.redalyc.org/html/1954/195415661005/>. Acesso em: 24 abr. 2018

GOMES, R.; PEREIRA, A. Estrutura de Capital. Review of Business and Legal Sciences / Revista de Ciências Empresariais e Jurídicas, n. 25 , p. 83- 96,1 ago. 2014

JENSEN, Michael C.; MECKLING, William H.. Theory of the firm: Managerial behavior, agency costs and ownership structure. In: JENSEN, Michael C.; MECKLING, William H.. Journal of Financial Economics. Rochester, Ny: El, 1976. p. 305-360.

DÍAZ-FERNANDEZ, María Carmen; GONZALEZ-RODRÍGUEZ, María Rosario. Top management demographic characteristics and company performance. In: PAWLAK, Marek. Industrial Management \& Data Systems. Seville, Spain: Emerald Insight, 2014. p. 365-386.

OLIVEIRA, Rossimar Laura; KRAUTER, Elizabeth. Teoria do Prospecto: Como Finanças Comportamentais Podem Explicar a Tomada de Decisão. Disponível

<http://www.fumec.br/revistas/pretexto/article/view/1863/artigo 7 - 3 2015>

SCHROEDER, Richard G.; CLARK, Myrtle W.; CATHEY, Jack M.. Financial Accounting Theory and Analysis. New York: Wiley, 2005.

SLOVIC, Paul. The Journal of Finance: Psychological Study of Human Judgment: Implications for Investment Decision Making. New York: Wiley, 1972 